\title{
Laboreal
}

Volume $16 \mathrm{~N}^{\circ} 1 \mid 2020$

Quando o trabalho real é tabu

\section{A governança pelos números contra a linguagem da atividade}

La gobernanza por números contra el lenguaje de actividad

La gouvernance par les nombres contre le langage de l'activité

Governance by numbers versus the language of activity

\section{Antoine Duarte e Roxane Dejours}

Tradutor. Laura Facury

\section{OpenEdition}

\section{Journals}

\section{Edição electrónica}

URL: http://journals.openedition.org/laboreal/15871

DOI: 10.4000/laboreal. 15871

ISSN: 1646-5237

\section{Editora}

Universidade do Porto

\section{Refêrencia eletrónica}

Antoine Duarte e Roxane Dejours, «A governança pelos números contra a linguagem da atividade », Laboreal [Online], Volume $16 \mathrm{~N}^{0} 1$ | 2020, posto online no dia 01 julho 2020, consultado o 08 julho 2020. URL : http://journals.openedition.org/laboreal/15871 ; DOI : https://doi.org/10.4000/laboreal. 15871

Este documento foi criado de forma automática no dia 8 julho 2020

\section{cc) (†) 8}

Laboreal está licenciado com uma Licença Creative Commons - Atribuição-NãoComercial 4.0 Internacional. 


\title{
A governança pelos números contra a linguagem da atividade
}

\author{
La gobernanza por números contra el lenguaje de actividad \\ La gouvernance par les nombres contre le langage de l'activité \\ Governance by numbers versus the language of activity
}

Antoine Duarte e Roxane Dejours

Tradução : Laura Facury

\section{NOTA DO EDITOR}

Manuscrito recebido em/Manuscrito recibido en : 07.02.2020

Aceite após peritagem/Aceptado tras peritaje en : 03.06.2020

Tradução : Laura Facury - laurafacury@gmail.com

\section{Introdução}

1 Apesar das controvérsias entre as concepções de ação e os métodos de intervenção em ciência do trabalho, uma ideia que parece ser compartilhada é a de que os trabalhadores e trabalhadoras possam tomar parte ativa na elaboração e nas transformações da organização do trabalho (Dejours, [1980] 2008 ; Lhuillier, 2006 ; Clot, 2010, Dugué, Petit, \& Daniellou, 2010).

2 Neste sentido, a questão da procura por eficiência nas práticas é, frequentemente, relacionada ao que Dugué, Petit et Daniellou chamaram de "ética da cidadania" (2010), através da qual pode-se reconhecer um interesse pelas condições éticas da vida democrática. Esse consenso, na França, é caracterizado pela uso em diferentes disciplinas e instâncias de um conceito, que foi primeiramente elaborado por Christophe Dejours, o de espaço de discussão (1992). 
3 No entanto, essa sensibilidade compartilhada em relação às questões sobre a democracia não elimina os desacordos e contradições que existem na forma de tratamento dos novos problemas apresentados pelas transformações do trabalho (Castel, 1995).

4 Por certo, há alguns anos, apareceram novas formas de organização do trabalho, assim como novos métodos de management [ $\left.{ }^{1}\right]$, regidos por uma governança pelos números [ $\left.{ }^{2}\right]$ (Supiot, 2015), o que caracteriza um redirecionamento, uma transformação, "da gestão" nas empresas e instituições (Dejours \& Duarte, 2018).

5 Assim, examinar os efeitos destas formas de organização em relação às possibilidades de transformação das situações do trabalho pelos próprios atores que contribuem para ela, os trabalhadores, nos parece imprescindível. Muitos de nós chamam a atenção para o fato de que essas novas organizações esgotam as potencialidades democráticas do trabalho (Cukier, 2016 ; Linhart, 2015 ; Duarte, 2017 ; Coutrot, 2018), e, pior, esgotam precisamente as potencialidades alcançadas através da deliberação e da cooperação.

Como?

7 Instaurando uma negação do real e do trabalho vivo, que constitui a pedra angular, e atacando a possibilidade de ter acesso ao trabalho efetivo [3]; tornando caduco e inaudível a linguagem da atividade - ou, em outros termos, a linguagem que permite a descrição subjetiva do trabalho por aqueles que o realizam concretamente. Por isso, não é surpreendente que os pesquisadores-clínicos, mais precisamente os pesquisadores que têm as ciências do trabalho como referência, encontrem dificuldades inéditas nas suas práticas de intervenção. Para compreender melhor a essência dessas dificuldades, nos baseamos em uma análise psicodinâmica de uma situação de trabalho em uma unidade de atendimento psiquiátrico.

Enquadramento metodológico

O trabalho apresentado é fruto de uma pesquisa-ação realizada por dois psicólogos/pesquisadores orientados por uma referência teórico-prática específica : a Psicodinâmica do Trabalho, no que concerne ao enquadramento das intervenções no ambiente de trabalho (AMT) [4] preconizadas pelos médicos do trabalho em suas atividades nos Serviços de Saúde do Trabalho (SST). o processo coletivo é uma investigação que tem como base a metodologia de enquete em psicodinâmica do trabalho (Dejours, [1980] 2008) : o ponto central dessa metodologia é o trabalho de elucidação pelos próprios trabalhadores sobre as ligações existentes entre a organização do trabalho e o sofrimento psíquico.

A investigação tem como objetivo produzir condições de discurso sobre a relação subjetiva com o trabalho a partir da fala dos trabalhadores que se voluntariam. 0 dispositivo proposto consiste na abertura de um espaço de elaboração coletivo para as pessoas em questão, e tem como objetivo a compreensão das motivações do sofrimento, assim como as motivações do prazer no trabalho ; as defesas erigidas para lidar com as dificuldades; e a história das transformações do trabalho.

A criação de um grupo permite a formalização de um enquadramento para a discussão e contribui para a criação de um espaço de deliberação diferente dos espaços informais que já existem, e diferente também das reuniões institucionais. o trabalho de elaboração se torna possível pela possibilidade de compartilhamento 
entre os trabalhadores, de colocar em palavras a experiência de trabalho de cada um. Nesta fase organiza-se um grupo constituído de voluntários dispostos a falar daquilo que vivem no trabalho, a escutar aquilo que os outros pensam e a tentar compreender juntos o que acontece.

Para alcançar esse objetivo insistimos em alguns pré-requisitos :

- O voluntariado é a condição sine qua non para o comprometimento da subjetividade na deliberação coletiva. Para compreender o que causa dificuldade é imprescindível a participação ativa na descrição do trabalho, o que não pode ser alcançado por um imperativo ou imposto.

- A confidencialidade das propostas é uma condição essencial durante o tempo da investigação para permitir, particularmente, a expressão de uma fala autêntica sobre o trabalho.

São previstas 5 reuniões de 3 horas com espaço de aproximadamente um mês entre elas. Os clínicos-pesquisadores são supervisionados entre as sessões por um outro clínico-pesquisador para discutir as dificuldades encontradas na enquete. No final de cada sessão produz-se um relatório "provisório", que será restituído ao grupo em uma reunião mais longa na qual o relatório é corrigido, enriquecido e enfim validado para a produção do relatório final. Este relatório apresenta as análises e interpretações dos clínicos-pesquisadores.

Sob a condição de um acordo entre os participantes voluntários do coletivo da enquete, e em comum acordo com a hierarquia, os clínico-pesquisadores realizam sessões de restituição e de discussão suplementares. 0 desenvolvimento dessa fase de restituição depende dos resultados do grupo de análise e das decisões dos participantes.

Em psicodinâmica do trabalho a produção de conhecimento repousa sobre o postulado da primazia do terreno. Este compreende que as conceptualizações partem do terreno, do drama vivido (Politzer, [1929] 2003) e têm como origem uma prática sempre concreta. Nessa perspectiva a elaboração conceitual é sujeita ao "primado da práxis" (Dejours, [1980] 2008, p. 223) ou o primado do trabalho vivo, como destacam K. Marx et F. Engels : "é aí que cessa a especulação, é na vida real que começa, então, a ciência real, positiva, a análise da atividade prática, do processo de desenvolvimento prático dos homens" [5] ([1845] 1968, p. 37). A psicodinâmica do trabalho faz referência, antes de mais, às investigações que são realizadas no campo, em situação real de trabalho. Dessa forma, o seu método é clínico e caracterizado pelo seu objeto inicial, "partindo do terreno, se desenrolando no terreno e retornando constantemente ao terreno" (Dejours, 1996, p. 198).

\section{Apresentação da enquete}

8 A enquete aconteceu em uma unidade de atendimento psiquiátrico de um grande grupo hospitalar, logo após um confronto físico entre profissionais de saúde. Este conduziu, a uma licença trabalhista de alguns meses de duração para uma das pessoas envolvidas devido à uma fratura múltipla no rosto e à suspensão de um outro cuidador como 
medida de precaução. 0 evento evidencia uma atmosfera que se tornou, de acordo com as palavras da diretora, "irrespirável há alguns meses já, no serviço, com a formação de clãs". Nós fomos, então, contatados pelo médico do trabalho que propôs uma intervenção com o objetivo de compreender melhor o que poderia ter acontecido no serviço para que um evento como este acontecesse. No momento do encontro com a diretora do estabelecimento ela demostra um grande sofrimento e chora algumas vezes enquanto evoca sua vivência do trabalho. Ela diz estar submersa pelas dificuldades que se acumulam e pelo ritmo das transformações na organização do trabalho impostas ao seu hospital.

9 Rapidamente concordamos sobre o que visar no processo de investigação. Proporíamos um espaço de elaboração coletiva aos agentes voluntários da equipe, com o objetivo de compreender como foi possível chegar a tal situação, e em um segundo momento, se o coletivo de voluntários desejasse, rediscutiríamos a situação baseada na elaboração das dificuldades vividas. A diretora, entusiasmada, reforça a importância de que essa forma de trabalhar seja, de acordo com suas próprias palavras, "participativa".

10 As questões preliminares do trabalho são, assim, guiadas pela necessidade de compreender como os profissionais experientes e que trabalham juntos há vários anos puderam chegar à violência física : esse comportamento poderia se justificar por uma fragilidade individual incrustrada em velhos rancores, ou seria fruto da relação desses profissionais com a organização do trabalho? Esse evento, ainda que condenado por todos os outros trabalhadores pode ser uma evidência de dificuldades compartilhadas por todos?

11 Claro que seria tentador interpretar o confronto como uma passagem ao ato ligada a uma fragilidade psíquica dos profissionais ou a histórias pessoais difíceis. Mais precisamente, o agir violento viria significar uma falha na atividade do pensamento e $o$ colapso das defesas individuais dos sujeitos perante uma situação do trabalho vivida como nefasta pela subjetividade.

12 Ora, a psicodinâmica do trabalho ressalta que para além da identificação dos transtornos psicopatológicos propriamente ditos, a questão essencial residiria, antes de tudo, na compreensão dos compromissos elaborados pela maioria dos homens e mulheres para manter o equilíbrio psíquico. Esse último se alcança em detrimento de entraves no trabalho, muitas vezes prejudiciais, com os quais eles e elas se confrontam. Nessa perspectiva é necessário, antes de tudo, compreender como os trabalhadores e as trabalhadoras dessa unidade puderam, até esse momento, exercer suas atividades sem incidentes importantes apesar das condições difíceis de trabalho. Por outro lado, é importante também possibilitar a abertura de um espaço coletivo de elaboração, pela via da metodologia específica da investigação clínica própria à psicodinâmica do trabalho. Apesar de não podermos apresentá-la em detalhes aqui (Dejours, [1980] 2008), é importante lembrar que ela representa, de fato, uma forma de "democracia provisória" (Daniellou, 2004, p. 118), ou seja, um deslocamento parcial da reflexão sobre o funcionamento usual da instituição.

13 Assim, um grupo de voluntários foi constituído, sendo que praticamente a totalidade dos agentes da unidade quis participar (14/17 dos trabalhadores da unidade, entre os quais psiquiatras, enfermeiras, auxiliares de enfermagem, auxiliares de limpeza, assistente social). A investigação durou 7 meses, durante os quais nos encontrámos 1 vez por mês para realizar sessões coletivas de uma duração de 3 horas. Na última sessão, que durou um dia inteiro, apresentamos aos participantes um relatório escrito 
no qual relatamos o processo de investigação e as interpretações colhidas sobre a relação entre sofrimento e organização do trabalho. Nesse momento, o relatório foi discutido, criticado e alterado pelo coletivo da enquete. Quando o relatório foi validado, os participantes decidiram seu destino e as modalidades de restituição.

14 Paralelamente, discutíamos frequentemente com a diretora do estabelecimento durante os primeiros meses do trabalho, o que a levou a desejar um acompanhamento também de sua equipe de gerência $\left.{ }^{6}\right]$; no entanto, ao longo do tempo nossas conversas se tornaram cada vez menos frequentes e ela não se abria a nós como ela o pôde fazer no início da investigação.

15 O trabalho realizado com os participantes permitiu, enfim, relançar a discussão sobre as questões do trabalho, apesar da rigidez do conflito. Mais precisamente, a agressividade e a severidade das defesas no início da investigação impediram o acesso ao real do trabalho. O deslocamento das defesas só foi possibilitado pois os participantes aceitaram se expor ao risco do desequilíbrio psíquico. Aos poucos começam a verbalizar, de fato, aquilo que os fazia sofrer realmente e concretamente, mobilizando a linguagem da atividade, o que lhes permitiu rediscutir sobre suas dificuldades, sobre o trabalho desleixado, ou ainda sobre os suicídios dos pacientes que se multiplicaram e sobre os quais ninguém fala; em resumo, eles falam sobre os seus sofrimentos e da experiência de compromisso, da traição da ética profissional no cotidiano de suas atividades.

16 "O suicídio de um paciente é como se tivesse se tornado normal, banal, como se fosse integrado ao funcionamento do HP [Hospital Psiquiátrico], pôde assim dizer uma enfermeira. Nós estamos na explicação pela fatalidade, é como se não pudéssemos fazer nada. Mas já é o quarto suicídio em 6 meses e isso não suscita nenhuma reunião, nenhuma interrogação coletiva. Eu não aguento mais esse silêncio e essa guerra entre nós, eu estou sem ar. Na verdade nós nos tornamos não humanos, e eu penso que não é mais possível. Nós não paramos, nem um minuto, por uma morte. E eu digo a vocês, as vezes eu penso que eu vou subir no quarto [andar] e... enfim."

17 Ao longo da investigação, a situação clínica se esclarece do ponto de vista das defesas mobilizadas contra o sofrimento ético [ $\left.{ }^{7}\right]$ e os participantes chegam a uma interpretação das razões da constituição dessas defesas tendo como referência central o trabalho : por fim compreendemos que as formações defensivas causaram conflitos importantes que geraram uma confrontação entre dois grupos; de um lado o grupo, dito, das "preguiçosas" e de outro lado o grupo dos "malvados". Essa formação em clãs fez com que os profissionais evitassem de falar daquilo que os fazia sofrer, focalizando, no lugar, dimensões interpessoais e defensivas que se enrijeceram nessa situação. Nessa perspectiva o trabalho de elaboração permitiu elucidar o sentido de algumas condutas e retomar a relação entre a experiência vivida e as transformações da organização do trabalho. Esse trabalho de elaboração é, sem dúvida, muito difícil para uma grande parte da equipe e nós nos inquietamos algumas vezes pelo equilíbrio psíquico de alguns participantes. É importante ressaltar que sem um engajamento deliberado dos participantes no trabalho de investigação, essa elaboração não seria possível. Ou seja, o engajamento é fruto da liberdade e da vontade e não poderia ser imposto de fora para dentro.

18 Finalmente a análise coletiva permitiu, antes de tudo, compreender como as transformações na gestão da organização do trabalho da instituição engendraram uma soma considerável de dificuldades para os profissionais. Mais precisamente, após uma auditoria proposta por consultores especializados em "management da saúde [sic]", há 
dois anos, a diretora decidiu introduzir, no estabelecimento, ferramentas de avaliação e protocolos de atendimento como uma forma de alinhar a oferta de atendimento do hospital com as normas nacionais e europeias preconizadas pela HAS [8]. A avaliação dos atendimentos visa, desde então, a eficiência e o custo dos tratamentos, assim como o grau de satisfação dos clientes. Instrumentos e ferramentas de medida foram colocados à disposição dos profissionais e servem, em contrapartida, para avaliá-los individualmente. Ressaltamos que essa forma de proceder é muito conhecida e foi, especialmente, descrita por Julien Dumesnil (2011) ; se trata da normatização do serviço de atendimento, que se baseia em um conjunto de ferramentas e de métodos : qualidade standard, Conferencia de consenso, Recomendações de boas práticas clínicas (RPC), Evidence Based Medicine (EBM) [], garantia da qualidade, certificações, etc - todos esses métodos constituem de facto a implementação de organização do trabalho gestionária. Para responder a esses métodos, os profissionais eram levados a dedicar uma grande parte do tempo de trabalho preenchendo da melhor forma esses documentos administrativos que eram demandados em massa pela direção. Alguns - aqueles chamados pelo qualificativo de "malvados" - pareciam ter se acomodado, e admitiram ter renunciado à reflexão e consentido obedecer às prescrições administrativas ou médicas mesmo lhes parecendo aberrantes. Por outro lado - "as preguiçosas" tentavam colocar essas diretivas em discussão, principalmente o aumento das prescrições de eletro-convulso-terapias $\left[{ }^{10}\right]$ pelos psiquiatras.

19 Posteriormente à investigação os participantes decidiram organizar uma restituição do relatório à diretora, na qual estavam presentes o médico do trabalho e nós mesmos. As modalidades de restituição foram discutidas pelos participantes e pela diretora; foi decidido, de comum acordo, convidar a equipe da diretoria (diretora clínica, diretora adjunta, diretor administrativo e financeiro, diretora do $\mathrm{RH}$ ).

\section{A restituição do relatório à direção}

Eis que as coisas se complicam. Diante da descrição subjetiva do trabalho apresentada pelos participantes, os membros da direção adotam uma postura bem particular : ao ler o relatório a diretora repreende o caráter não-objetivo dos elementos interpretativos relatado pelos profissionais da unidade e ressalta que aquilo que os profissionais disseram vai contra a certificação realizada pela HAS algum tempo antes. No seu ponto de vista, a experiência vivida pelos profissionais "não reflete a realidade" e que precisaria ser mais "pedagógica" - dito de outra forma, de explicar melhor as razões das transformações do trabalho. Além disso, ressalta que já tinha pensado em um "plano de ação para colocar em prática". Ela nos explica, então, que havia encomendado uma sondagem BVA [11] para medir de forma mais "precisa e menos subjetiva" a qualidade de vida no trabalho e o clima social. Ao receber os resultados dessa sondagem, ela pretendia convocar um gabinete de consultoria para colocar em prática um "processo participativo" com os grupos de trabalho, para permitir às pessoas "se adaptarem melhor" às transformações da instituição. Além disso, a diretora adjunta propôs um novo plano de comunicação já que, de acordo com suas próprias palavras, ela não "expôs suficientemente o sentido" para que os profissionais compreendessem as mutações necessárias que eles deveriam realizar para se adaptarem às transformações da sociedade francesa e desse mundo "em ruptura". Enfim, o diretor clínico afirma que as "disfunções" apresentadas no relatório escrito 
estão relacionadas com um déficit de respeito pelos procedimento preconizados pela HAS e que ele iria, então, se esforçar para explicar melhor a necessidade de respeitá-los. Apesar das discussões que seguiram, foi impossível uma flexibilização da racionalidade gestionária e o muro da negação que ela impõe à atividade como ela é concretamente realizada e vivida. In fini, foram, inclusive, essas preconizações que foram colocadas em prática posteriormente.

21 Contudo, durante essa enquete a diretora nos pareceu aberta e seu sofrimento inicial não nos permitia imaginar tal desfecho. Entre nossos primeiros encontros e a restituição final ela havia começado um trabalho de coaching psicológico proposto e financiado pela instituição hospitalar - que só chegou ao nosso conhecimento posteriormente -, e estava participando de um seminário, com a equipe de direção, endereçado aos gerentes dirigentes. $O$ que, em si, não é surpreendente se entendermos que, na França, as políticas organizacionais praticadas pelo New Public Management conduzem, de forma geral, a modalidades de tratamento específicas que levam à desestabilização psíquica dos dirigentes da instituição hospitalar : é frequente a oferta de acompanhamentos psicológicos aos dirigentes, normalmente proposta por consultores e tendo como objetivo permitir-lhes suportar, se adaptar e "resistir" às obrigações do trabalho relativas à instauração das transformações do trabalho, sem que seja possível o questionamento do ponto de vista subjetivo (ver por exemplo Belorgey, 2010). Essa diretora não é cínica - longe disso, poderíamos dizer - e ela estava muito afetada quando nos encontramos; isso não altera o fato de que, provavelmente, a segurança oferecida pela linguagem e pela ideologia gestionária, do ponto de vista do seu equilíbrio psíquico, tenham tido um efeito muito mais atrativo que o trabalho de se colocar em questão, permitindo-a, assim, evitar a angústia se apoiando na ideologia colocada à disposição pelas sessões de coaching de gestão.

Nos parece evidente que não podemos minimizar o fato de que o fracasso deste trabalho e a impossibilidade de relançar a discussão sobre a organização do trabalho foi, pelo menos em parte, nossa responsabilidade e pode estar ligado também a um déficit de habilidade.

Entretanto, os limites pessoais não poderiam constituir a única razão desse retorno pois a experiência nos revela que, já há alguns anos, muitos clínicos e pesquisadores experientes vivem fenômenos similares de forma cada vez mais frequente. Encontramos essa repetição em vários contextos, mas em particular nas organizações atingidas de forma importante pela reforma do estado neo-liberal e do New Public Management.

\section{0 número e a gestão contra a linguagem da atividade}

Como, portanto, apreender as incidências das novas formas de organização do trabalho sobre a capacidade de ação dos trabalhadores?

Dois pontos nos parecem essenciais :

Primeiramente, a dimensão pática da relação com o trabalho deve ser examinada. Em outras palavras, a relação com o trabalho enquanto vivência afetiva, e que configura origem de experiências variadas de prazer e de sofrimento. Como nos mostra a psicodinâmica do trabalho, esse sofrimento motiva a formação de estratégias de defesa 
que podem funcionar como anestésicos e inclusive, a formação em clãs como descrito acima, pode ser uma consequência. As estratégias de defesa são constituídas, em parte, pela eufemização da percepção do sofrimento, e constituem um obstáculo importante à verbalização e à comunicação da relação subjetiva com o trabalho. Como consequência as defesas contribuem com o apagamento da linguagem da atividade, única capaz de relançar a discussão sobre o trabalho efetivo (trabalho real) e sua organização, em detrimento de uma linguagem defensivo-denunciadora edificada por defesas.

27 Em segundo lugar, é importante destacar que em toda organização do trabalho, o trabalho vivo se faz objeto de controle por uma hierarquia, de vigilância, de gestão. Em outras palavras, para além da divisão técnica das tarefas, a organização do trabalho mobiliza, sempre, um método rigoroso de dominação. Nos parece, então imprescindível considerar de forma lúcida as novas formas de dominação relativas à organização gestionária do trabalho.

28 De fato, os gestores concebem uma gestão unicamente com base em indicadores quantitativos que lhes permitiria ter acesso a "ilusões da subjetividade" e principalmente admitem um apagamento da atividade dos profissionais de saúde. Nessa lógica, a única verdade reside nas medições e na avaliação quantitativa das "auditorias", que se constituem como forma paradigmática. Com o objetivo de impor essa concepção à direção, designada então como governança, são utilizados alguns dispositivos, como os que nós encontrámos nesse hospital psiquiátrico e que são baseados na avaliação das performances, de critérios de qualidade total, da normalização e estandardização de modos operatórios, etc. Em outros termos, estamos diante de uma nova linguagem que bloqueia o desenvolvimento do pensamento: se trata de uma nova língua managerial e gestionária (Vandevelde-Rougale, 2017), que desqualifica a linguagem da atividade e como consequência, a relação com o real, a fala relativa ao trabalho real, não tem mais lugar. Vejamos a fala da antiga ministra da saúde francesa, Agnès Buzyn, ao ser confrontada com elementos das vivências dos profissionais da saúde dos hospitais psiquiátricos : "nós não podemos dizer que hoje os pacientes não passam pelos hospitais sem uma certificação". Essa resposta que se baseia na certificação, restringe ao absurdo os elementos evocados pelos trabalhadores e confirma a recusa de escutar qualquer coisa da ordem do real do trabalho como uma impossibilidade irremediável de deliberar (Duarte, 2018).

29 O material de base de nossas intervenções se mostrou inútil, não podendo mais nutrir nossas práticas da mesma forma que antes; mais precisamente, a linguagem da atividade, descreditada pela linguagem e dispositivos gestionários, não é mais capaz de servir de substrato à atividade do pensamento. A palavra viva é esvaziada e nós nos deparamos com o que propomos chamar de impossibilização [12] de deliberação sobre o trabalho vivo. Esse processo de impossibilização se constrói a partir da abstração dos números, materializada pela utilização massiva de tabelas Exel, de indicadores de avaliação quantitativos e ferramentas de medida como os questionários. Esse processo representa, assim, o pilar da dominação neoliberal do trabalho.

30 Desta forma, seria ainda possível pensar na nossa prática em uma situação em que a fala sobre o trabalho efetivo se confronta com uma linguagem que tem como qualidade fundamental o empobrecimento (Klemperer, [1947] 1996) ? Como fundar nossa prática sobre uma ética da discussão quando seu suporte fundamental, a linguagem, é "encardida e envenenada" (Ibid., p. 24) pelo léxico da gestão neoliberal ? Como reinstaurar uma deliberação em uma organização dirigida por managers, que não 
querem saber sobre o trabalho real e que pretendem "governar sob a base de dados quantitativos supostamente capazes de dizer a verdade sobre o trabalho sem precisar passar pela análise das formas concretas da atividade dos assalariados" (Dejours, in Auslender, 2017, p. 205)?

\section{Como a linguagem do número e da gestão é incorporada?}

31 Para responder a essa questão é preciso passar pela compreensão de que maneira a língua se insinua na carne e no corpo dos indivíduos até que modifique a percepção, o vivido e a compreensão de uma situação. Para isso, é preciso, em um primeiro momento, existir uma produção de expressões prontas, de slogans, de estereótipos, de imagens exemplares, de formas sintáticas específicas e de neologismos que constituirão o substrato dessa linguagem e participarão da criação de um imaginário social (Le Goff, 1985 ; Dejours, 2001 ; Dejours, 2017 ; Gernet, 2017). Esse trabalho de produção tem sua fonte nos departamentos de comunicação e nos conselhos de comunicação das empresas e instituições, com a ajuda dos "Think Tank" de todos os tipos, os "spin doctors" dos partidos políticos ou ainda as produções da indústria cultural - filmes, programas de televisão, livros, etc. (Horkheimer \& Adorno, [1947] 1983).

Compreender como os sujeitos mobilizam e incorporam essa língua, essas palavras, essas maneiras de dizer pressupõe considerar que exista nos próprios sujeitos, uma parte ativa nessa apropriação, como ressalta a psicodinâmica do trabalho. Em outras palavras, a língua não se inocula como um agente tóxico ao qual o sujeito foi exposto de forma passiva : ela não pode ser incorporada a não ser que o sujeito a faça entrar, ativamente, por três razões.

Em primeiro lugar por questões de reconhecimento : aquele que mobiliza as palavras prescritas pela linguagem "oficial" aumentará suas possibilidades de evoluir na organização do trabalho (Duarte, 2017). Assim, o carreirismo e o desejo de reconhecimento institucionais são motivações privilegiados da linguagem gestionária.

Em segundo lugar a dimensão pática, relativa à preservação da saúde mental, permite compreender a referência à linguagem gestionária e managerial. As estratégias coletivas têm como pilar a referência ideológica, um imaginário social. Nessa perspectiva, a parte ativa do sujeito se situa nas estratégias coletivas de defesa mobilizadas por este para lutar contra aquilo que o faz sofrer na atividade do trabalho; a negação do real, produzido pelas defesas ao mobilizar o imaginário social, oferece aos trabalhadores $\mathrm{e}$ trabalhadoras a possibilidade de reduzir o campo de percepção para não mais ver o que os faz sofrer. No caso da nossa investigação, os cuidadores se defendem da confrontação com a possibilidade de que eles mesmos podem ter participação na degradação do atendimento aos pacientes. Assim, mobilizam esforços para não pensarem no sentido de algumas passagens ao ato suicida, nem nas consequências da redução do tempo clínico com os pacientes, nem mesmo da possibilidade de terem deixado pacientes com fome ao obedecerem às novas medidas tomadas pelo grupo de acionistas da estrutura : com o objetivo de responder à política de redução de custos um racionamento da comida foi colocado em prática algum tempo antes da nossa investigação; os cuidadores foram instruídos a não dar mais comida aos pacientes fora do horário das refeições ou mesmo de não voltar a servir os pacientes - aqueles que transgrediram 
foram designados como "gentis demais" e denunciados como aqueles que não respeitam o enquadramento e "não respeitam as regras de alimentação". Da mesma forma o recurso à eletro-convulso-terapia, usado as vezes de forma abusiva, não era questionado, mesmo que os cuidadores tenham percebido consequências destrutivas nos pacientes, tanto somáticas quanto psíquicas (empobrecimento mental a curto e longo prazo, desestruturação das competências neuro-cognitivas ou ainda, menos frequente, crises epiléticas). Para lutar contra o sofrimento ético gerado por esses atos os cuidadores se defendem por uma forma de retorno à razão ; não podendo assumir sua participação subjetiva ao que aparece como maus-tratos, eles acusam os outros, particularmente os "usuários" - dito de outra forma, os pacientes: os pacientes depressivos não seriam "verdadeiros pacientes", seriam na verdade considerados como "clientes no hotel"; é percebido um aumento no uso de drogas por esses pacientes, o que gera uma resposta de enrijecimento dos limites e aumento da monitorização ; por fim diante da violência e do perigo apresentado por alguns pacientes, seria necessário melhorar a segurança (pela presença de guarda costas nos serviços e de portas de segurança). Onde deveria se construir um pensamento clínico relativo aos pacientes e às suas problemáticas psicopatológicas, se desenvolve uma luta de clãs erigida pelo recurso a um pensamento estereotipado, que mobiliza particularmente o imaginário securitário e opera uma inversão da responsabilidade da degradação da situação, o que permite manter um conforto psíquico considerável entre os cuidadores.

Em terceiro lugar, para se estruturar a linguagem da atividade precisa se basear na produção de regras, particularmente linguísticas, nomeadas atividades deônticas (Dejours, 2009). Quando os espaços de deliberação se reduzem devido às transformações da organização do trabalho, é justamente essa capacidade coletiva de nomear e descrever o trabalho que é atacada. Assim, é num registro deficitário que podemos compreender a dominação da linguagem gestionária: mais precisamente, os trabalhadores e trabalhadoras não dispõem mais de palavras para descreverem suas atividades. Em consequência disso, para poderem falar e se fazerem entender, os cuidadores são obrigados a utilizar a linguagem gestionária para descreverem o próprio mundo do trabalho. $O$ déficit semiótico faz com que os cuidadores só possam descrever o trabalho, no espaço público interno à organização do trabalho, a partir de uma descrição oferecida pelos gestionários, e não uma descrição que estaria de acordo, ou determinada pelo ofício.

\section{Lutar contra a dominação simbólica da razão gestionária}

Nessa perspectiva, lutar contra a dominação simbólica imposta pela linguagem do número e da gestão incita duas ações determinantes :

1. A produção de novas descrições do mundo do trabalho permitindo reconhecer o trabalho vivo e os elementos oriundos do real. A ideia aqui não é produzir um novo imaginário social, mas sim conceitos clínicos que permitam desconstruir através de uma "semiotização da experiência do trabalho e do sofrimento no trabalho" (Dejours, 2010, p. 64). Conferimos aqui um lugar importante aos artistas e especificamente aos cineastas e aos envolvidos com o teatro nesse trabalho de produção e de desconstrução das descrições do trabalho (Dejours \& Duarte, 2018). 
2. A elaboração coletiva, operada pelos trabalhadores mesmos, sobre sua relação subjetiva com o trabalho é uma atividade decisiva para deslocar ou mesmo derrotar as estratégias de defesa coletiva, ela tem como o objetivo repensar as dificuldades do trabalho e renovar os modos de agir.

37 Em outras palavras, o desenvolvimento da resistência a essas lógicas organizacionais repousa em parte em uma "reconquista do direito de falar" (Dejours, 2010), passando inevitavelmente por uma contestação da dominação simbólica enraizada na retórica e em formas linguísticas que mantêm a ordem social.

Como clínicos do trabalho e cientistas, a descrição que fazemos é baseada, tanto quanto possível, na realidade ou, mais precisamente, na relação com a realidade e o sofrimento. Se nos basearmos no real, não existe interdição de fala. E quando somos capazes de evidenciar a diferença entre a descrição subjetiva e a descrição gestionária, podemos revelar a falsidade de uma descrição. Realizar esse trabalho de desconstrução das linguagens de dominação simbólica parece ser nossa tarefa como clínicos e pesquisadores. Infelizmente, nem sempre temos sucesso e o fracasso pode-se mostrar amargo, como na investigação nesta unidade de atendimento psiquiátrico.

A experiência que vivemos nos faz sentir, como aos participantes, uma raiva por não sermos capazes de nos fazer entender e ouvir. Pior, não conseguimos dizer o que queríamos dizer : estávamos presos pela linguagem gestionária e pela razão do número. No entanto, isso não impediu completamente que algo fosse transformado em outro nível.

\section{Rumo à resistência baseada no trabalho vivo}

Ao final desta investigação, notamos que os participantes experienciavam uma forma de prazer de encontrar-se durante as sessões mensais de investigação, além disso ao longo do processo foi crescendo a importância conferida ao trabalho de elaboração coletiva. Em outras palavras, à medida que as sessões prosseguiram, sentimos que uma certa confiança começou a se recompor, com base na cooperação concreta e discreta. Os participantes finalmente explicam, semelhante ao que podemos ver em outras pesquisas, que este trabalho lhes permitiu sair de uma forma de solidão. Alguns contam como eles conseguiram se envolver novamente em discussões sobre os pacientes com colegas com quem eles não conseguiam conversar até então.

41 Após a restituição, durante a qual tentam argumentar e descrever a situação vivida, alguns deles ficam desestabilizados, alguns irritados, por experimentarem esse desprezo baseado na negação do trabalho real e de sua inteligência. No entanto, eles não desanimaram e, em seguida, entraram em contato conosco para participarmos de algumas reuniões e compartilhar as conclusões da investigação com colegas que não participaram do trabalho. Essas reuniões ocorreram em uma sala do sindicato, fora do hospital. Eles dizem ter conseguido "construir algo precioso" e tentam "encontrar significado" no que fazem. Mobilizados pela vontade comum de cuidar melhor de seus pacientes, eles tentam criar uma cooperação por vias mais clandestinas, longe dos dispositivos gestionários da instituição. Nos espaços que eles reconstruíram, o trabalho efetivo não é mais "tabu"; eles falam sobre situações e pacientes e, nesse espaço, a atividade deles não é um objeto impuro atingido pela proibição de dizer ou pela negação imposta pela novilingua e pelas práticas organizacionais neoliberais. Pois é preciso dizer, a negação organizada por essa linguagem, em última análise, só pode 
gerar as bases comuns a qualquer sociedade totalitária. Ao se comprometerem com a realização de um trabalho comum escondido dos olhos da direção, e no qual a discussão sobre os pacientes ocupa o lugar central, os participantes abrem caminho para que o trabalho se torne o que deveria ser em qualquer organização do trabalho verdadeiramente humana : um objeto de deliberação. É nessa condição que ele pode ser um terreno fértil para as potencialidades da resistência à governança pelos números (Duarte, 2017).

\section{BIBLIOGRAFIA}

Auslender, V. (2017). Omerta à l'hôpital. Paris : Michalon.

Belorgey, N. (2010). L’hôpital sous pression. Paris : La découverte.

Castel, R. (1995). Les métamorphoses de la question sociale. Paris : Fayard.

Clot, Y. (2010). Le travail à cœur. Pour en finir avec les risques psychosociaux. Paris : La Découverte.

Coutrot, T. (2018). Libérer le travail. Paris : Seuil

Cukier, A. (2014). Pouvoir et empathie. Philosophie sociale, psychologie et théorie politique. (Thèse de doctorat). U.F.R. PHILLIA (Philosophie, Information-Communication, Langage, Littérature, Arts du spectacle), Université Paris-Ouest Nanterre, France.

Cukier, A. (2016). Le néolibéralisme contre le travail démocratique. Contretemps, 31, 30-44

Daniellou, F. (2004). Synthèses du séminaire. In Actes du séminaire Anact, Les conditions d'une prévention durable des TMS (pp. 114-120). Paris : ANACT.

Dejours, C. ([1980] 2008). Travail, usure mentale. Paris : Bayard.

Dejours, C. (1992). Pathologie de la communication, situations de travail et espace public : le cas du nucléaire. In A. Cottereau et P. Ladriere (s/dir.), Raisons pratiques (vol 3, pp. 177-201). Paris : Editions de l'Ecole des hautes études en sciences sociales.

Dejours, C. (1995). Le facteur humain. Paris : PUF.

Dejours, C. (1996). Psychologie clinique du travail et tradition compréhensive, In Y. Clot (Dir.), Les histoires de la psychologie du travail, pp. 197-220. Toulouse : Octarès.

Dejours, C. ([1998] 2009). Souffrance en France. Paris : Le Seuil.

Dejours, C. (2001). Le corps, d'abord. Paris : Petite Bibliothèque Payot.

Dejours, C. (2009). Travail vivant (Tome 2), Travail et émancipation. Paris : Payot.

Dejours, C. (2010). Le travail entre souffrance individuelle, intelligence collective et promesse d'émancipation. Le sujet dans la cité, 1(1), 59-72. https://doi.org/10.3917/lsdlc.001.0059

Dejours, C., \& Duarte, A. (2018). La souffrance au travail : révélateur des transformations de la société française, Modern \& Contemporary France, 2, 232-244. https://doi.org/ 10.1080/09639489.2018.1445707

Dejours, R. (2017). Du rappeur américain à l'ingénieur criticien. Ascension sociale et structuration des idéaux, Psychologie clinique et projective, 23, (1), 45-68. https://doi.org/10.3917/pcp.023.0045 
Dugué, B., Petit, J., \& Daniellou, F. (2010), L'intervention ergonomique comme acte pédagogique, Pistes, http://www.pistes.uqam.ca/.

Duarte, A. (2017). Résistance et défenses en psychodynamique du travail, (Thèse de doctorat), Laboratoire de Psychologie Clinique, Psychopathologie, Psychanalyse (EA 4056), Université ParisDescartes, Paris, France.

Duarte, A. (2018). Résistance et travail vivant : les apports de la psychodynamique du travail, Travailler, 40, 2, 135-146. https://doi.org/10.3917/trav.040.0135

Dumesnil, J. (2011). Art médical et normalisation du soin. Paris : PUF. https://doi.org/10.3917/ puf.dumes.2011.01

Gaudart, C., \& Rolo, D. (2015). L'ergonomie, la psychodynamique du travail et les ergodisciplines. Entretien avec François Daniellou. Travailler, 34(2), 11-29. https://doi.org/10.3917/trav.034.0011 Gernet, I. (2017). Travail de la pensée et imaginaire social. In Dejours, C. \& Tessier, H. (Dirs.) Laplanche et la traduction : une théorie inachevée (pp. 149-165). Paris : PUF.

Horkheimer, M., \& Adorno, T. ([1947] 1983). La Dialectique de la raison. Paris : Gallimard.

Klemperer, V. ([1947]1996). LTI La langue du III ${ }^{e}$ Reich. Paris : Albin Michel.

Le Goff, J. (1985). L'imaginaire médiéval. Paris : Gallimard.

Linhart, D. (2015). La comédie humaine du travail. Toulouse : Erès. https://doi.org/10.3917/ eres.linha.2014.01

Lhuilier, D. (2006). Cliniques du travail. Toulouse : Erès. https://doi.org/10.3917/eres.lhuil.2007.01

Marx, K., \& Engels, F. ([1845] 1968). L’idéologie allemande. Paris : Editions sociales.

Politzer, G. ([1929] 2003). Critique des fondements de la psychologie. Paris : PUF.

Supiot, A. (2015). La Gouvernance par les nombres. Cours au Collège de France (2012-2014). Paris :

Institut d'études avancées de Nantes/Fayard.

Vandevelde-Rougale A. (2017). La Novlangue managériale. Toulouse : Erès. https://doi.org/10.3917/ eres.vande.2017.01

\section{NOTAS}

1. [Nota da tradutora] o texto em francês conserva a palavra de origem inglesa. Diante disso decidimos também mantê-la em inglês na tradução, diferenciando-a do que poderíamos traduzir como "gerência".

2. A gestão pelos números [Gouvernance par les nombres na versão original] é, para Alain Supiot, o projeto político sustentado pelo movimento capitalista de "globalização". o sentido do poder é fundamentado com base em um ideal normativo, que visa a realização eficaz de objetivos passível de medição por indicadores quantitativos ao invés da obediência às leis justas produzidas por uma instância transcendente soberana da sociedade.

3. Damos preferência à expressão trabalho efetivo ao invés de trabalho real para não gerar confusões com o real do trabalho que, em Psicodinâmica do Trabalho designa aquilo que resiste ao controle do trabalhador em relação à própria e ao savoir-faire da pessoa que trabalha (Dejours, 1995). O trabalho efetivo designa o trabalho enquanto na realização efetiva, tal como como o trabalho real para os ergonomistas.

4. [Nota da tradutora] A sigla em francês é actions en milieu de travail (AMT).

5. [Nota da tradutora] Tradução livre. 
6. [Nota da tradutora] Na versão francesa : cadre. Posição de enquadramento de um serviço ou uma equipe.

7. O sofrimento ético tem sua origem no fato de que o sujeito realiza atos que vão contra o seu senso moral (Dejours, [1998] 2009).

8. A Autoridade máxima de saúde [em francês Haute Autorité de Santé] (HAS) é uma autoridade pública francesa independente que tem como missão avaliar, do ponto de vista médico e econômico, os produtos, atos e tecnologias da saúde. Ela também define as recomendações da boa prática clínica, as recomendações de saúde pública, os guias de atendimento endereçados aos profissionais e aos pacientes. Certifica, ainda os estabelecimentos de saúde.

9. [Nota da tradutora] Em inglês na versão original.

10. A eletro-convulso-terapia (ECT) é uma prática de tratamento pela eletricidade utilizada em psiquiatria, que consiste em aplicar no couro cabeludo do paciente uma corrente elétrica de intensidade variável. Esse método já foi, em um momento da história, chamado de terapia eletroconvulsiva ou tratamento por eletrochoque.

11. [Nota da tradutora] BVA é uma empresa de sondagens e estudos de marketing muito importante na Europa e fora da Europa.

12. [Nota da tradutora] Na versão francesa : imposibilisation. Neologismo criado por Cukier.

\section{RESUMOS}

A partir de uma pesquisa em psicodinâmica do trabalho, o artigo procura esclarecer as consequências das novas formas de organização do trabalho na atividade de deliberação e cooperação dos trabalhadores por um lado, nas possibilidades de desenvolvimento e ações por outro lado. Preocupa-se particularmente em mostrar como a negação da realidade e o trabalho vivo, apoiada pelas transformações gerenciais na organização do trabalho, desqualificam a linguagem da atividade emanada pelos trabalhadores e impedem o acesso ao trabalho eficaz, “impossibilitando" a deliberação sobre o trabalho vivo. Por fim, questiona as condições necessárias para o restabelecimento da deliberação, de modo a ter precedência sobre um pensamento invadido pelo imaginário social e que possa abrir caminho para o desafio da dominação simbólica e para a resistência à governança pelos números.

A partir de una investigación en psicodinámica del trabajo, el artículo quiere explicar las consecuencias de las nuevas formas de organización del trabajo sobre la actividad de deliberación y la cooperación entre los trabajadores, por un lado, sobre las posibilidades de desarrollo de la acción por otra parte. Los autores muestran cómo la negación de "lo real" y del trabajo vivo, respaldada por las transformaciones manageriales en la organización del trabajo, descalifica el lenguaje de la actividad que emana de los trabajadores y prohíbe el acceso al trabajo efectivo, "imposibilitando" por lo tanto la deliberación sobre el trabajo vivo. Finalmente, cuestionan las condiciones necesarias para restablecer la deliberación, de modo a sobrepasar un pensamiento invadido por el imaginario social y para ver la manera de abrir el camino a la contestación de la dominación simbólica y a la resistencia a la gobernanza por números.

À partir d'une enquête en psychodynamique du travail, l'article vise à expliciter les conséquences des nouvelles formes d'organisation du travail sur l'activité de délibération et la coopération des travailleurs d'une part, sur les possibilités d'élaboration et d'action de ces derniers d'autre part. 
Il s'attache notamment à montrer comment le déni du réel et du travail vivant, soutenu par les transformations gestionnaires de l'organisation du travail, disqualifie le langage de l'activité émanant des travailleurs et barre l'accès au travail effectif, “impossibilisant " dès lors la délibération sur le travail vivant. Enfin, il interroge les conditions nécessaires à une réinstauration de la délibération, afin que celle-ci reprenne le pas sur une pensée envahie par l'imaginaire social et que puisse s'ouvrir la voie de la contestation de la domination symbolique et de la résistance à la gouvernance par les nombres.

Starting from a research in psychodynamics of work, the paper aims to explain the consequences of the new forms of work organization on the activity of deliberation and cooperation of workers, on the one hand, and on their possibilities of development and action, on the other hand. It is particularly concerned with showing how the denial of reality and living labor, supported by managerial transformations in the organization of work, disqualifies the language of activity emanated from workers and bars access to effective work, thus "preventing" deliberation on living labor. Finally, it questions the necessary conditions for a reinstatement of deliberation, so that it takes precedence over a thought invaded by the social imaginary and that can open the way to the challenge of symbolic domination and to the resistance to governance by numbers.

\section{ÍNDICE}

Palabras claves: deliberación, newspeak, gobernanza por números, actividad, psicodinámica laboral

Keywords: deliberation, newspeak, governance by numbers, activity, psychodynamics of work Palavras-chave: deliberação, novilingua, governança pelos números, atividade, psicodinâmica do trabalho

Mots-clés: délibération, novlangue, gouvernance par les nombres, activité, psychodynamique du travail

\section{AUTORES}

\section{ANTOINE DUARTE}

Université Toulouse Jean Jaurès (LPS-DT), 5 allée Antonio Machado, 31058 Toulouse antoine.duarte@ipdt.fr

\section{ROXANE DEJOURS}

Laboratoire de psychologie clinique, psychopathologie, psychanalyse (PCPP, EA 4056), Institut de Psychologie, Université Paris Descartes, Sorbonne, 71 avenue Edouard Vaillant, 92100 BoulogneBillancourt roxanedejours@gmail.com 